\title{
Seasonal Variation of Phytochemicals in Four Selected Medicinal Plants
}

\author{
Bonface Mwamatope ${ }^{1}$, David Tembo ${ }^{2, *}$, Elizabeth Kampira ${ }^{3}$, Cecilia Maliwichi-Nyirenda ${ }^{4}$, Victoria Ndolo ${ }^{5}$
}

\section{Bonface Mwamatope ${ }^{1}$, David Tembo 2,* Elizabeth Kampira ${ }^{3}$, Cecilia Maliwichi-Nyirenda ${ }^{4}$, Victoria $\mathrm{Ndolo}^{5}$}

'Biomedical Sciences Department, College of Medicine, University of Malawi, Blantyre, MALAWI.

${ }^{2} P$ hysics and Biochemical Sciences Department, The Polytechnic, University of Malawi, Blantyre, MALAWI. ${ }^{3}$ Medical Laboratory Department, College of Medicine, University of Malawi.

${ }^{4}$ Research Support Centre, College of Medicine, University of Malawi, Blantyre, MALAWI.

${ }^{5}$ Department of Human Ecology, Faculty of Science, Chancellor College, University of Malawi, Blantyre, MALAWI.

\section{Correspondence}

David Tembo

Physics and Biochemical Sciences Department, The Polytechnic, University of Malawi, Blantyre, Malawi.

Tel.: +265 (0)1 872911 Ext. 1156.

E-mail address: dtembo@poly.ac.mw.

History

- Submission Date: 21-04-2021;

- Review completed: 10-05-2021.

- Accepted Date: 01-06-2021

\section{DOI : 10.5530/pres.13.4.14}

Article Available online

http://www.phcogres.com

Copyright

(C) 2021 Phcog. Net. This is an openaccess article distributed under the terms of the Creative Commons Attribution 4.0 International license.

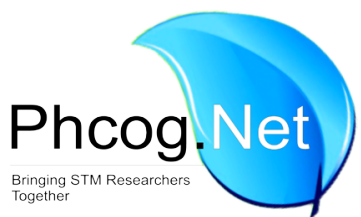

\section{ABSTRACT}

Background: The study aimed at assessing total alkaloids content (TAC), total flavonoids content (TFC), total phenolic content (TPC), antioxidant activity (AA) and predominant individual phenolic compounds in methanol extracts of $M$. oleifera, S.singueana, M.azedarach leaves and stem barks of $L$. discolor collected during different seasons of the year. Materials and Methods: TPC, TFC and TAC were analyzed using the Folin Ciocalteau assay, aluminum chloride assay and bromocresol green assay, respectively. 2,2-diphenyl-1-picrylhydrazyl (DPPH) and ferric reducing antioxidant power (FRAP) techniques were used to analyse AA. Phenolic compounds; Vanillic acid, (+)-catechin, quercetin, rutin, sinapic acid, 2,4-hydroxybenzoic acid and ferulic acid were analyzed using high performance liquid chromatography diode array detector (HPLC - DAD). Results: Barks of $L$. discolour exhibited high levels of TPC, TFC, TAC and AA during hot-dry season (summer) as compared to S. singueana, M. oleifera and $M$. azedarach leaves which showed significantly $(p<0.05)$ higher levels in hot-wet season (rainy). Levels of TPC, TFC and TAC were significantly $(p<0.05)$ influenced by seasonal variations and correlated with levels of AA. Profiles of all phenolic compounds analyzed were not similar in terms of chemical composition and concentration during different seasons. Sinapic acid and 2,4-hydroxybenzoic acid were predominant in S. singueana while sinapic acid and ferulic acid were predominant in $M$. oleifera. Vanillic acid and 2,4-hydroxybenzoic acid were predominant in L. discolor and M. azedarach respectively. Conclusion: The phytochemical constituents in medicinal plants are subject to seasonal variations which in turn influence the optimum season of harvesting.

Keywords: Alkaloids, Antioxidant activity, Flavonoids, Medicinal plants, Phenolic compounds, Seasonal variations.

\section{INTRODUCTION}

There is increase in the use of plants as medicines world-wide, due to lack of access to conventional drugs, financial challenges and the ineffectiveness and side-effects of some conventional drugs. ${ }^{[1-3]}$ Plant parts such as roots, leaves and barks are usually used as medicinal agents and sources of natural bioactive compounds that work for treatment of different ailments and as natural antioxidants. ${ }^{[4,5]}$ These bioactive compounds such as flavonoids, anthraquinones, stilbenes, terpenes, alkaloids, tannins, saponins and phenolic compounds are synthesized in plants via different pathways, such as shikimic acid, salonic acid, mevalonic acid and non-mevalonate. ${ }^{[6,7]}$ In many African countries including Malawi, some of these medicinal plants (e.g. S. singueana, L. discolor, M. oleifera and $M$. azedarach) are used for treatment of different diseases. ${ }^{[8-13]}$

Senna singueana also known as wild Cassia whose family is Fabaceae is used a lot in Africa for treating various ailments. ${ }^{[8,10]}$ It has been claimed that this plant is effective in managing skin cancer, ${ }^{[8,14]}$ diabetes, constipation, stomach pains, sexually transmitted

Cite this article: Mwamatope B, Tembo D, Kampira E, Maliwichi-Nyirenda C, Ndolo V. Seasonal Variation of Phytochemicals in Four Selected Medicinal Plants. Pharmacog Res. 2021;13(4):218-26. infections, inflammation, fever and malaria. ${ }^{[15-17]}$ Melia azedarach is a species of medicinal plant in Meliaceae family. ${ }^{[18,19]}$ Some of reported pharmacological activities of this species include hepatoprotection, anti-fertility, antioxidant, anti-viral, anti-bacterial, wound healing, analgesic, insecticidal and anticancer. ${ }^{[1,20,21]}$ Moringa oleifera belongs to a family of Moringaceae and is used to treat different ailments and prevent malnutrition. ${ }^{[9,11]}$ The plant parts of M. oleifera possess some biological activities such as anti-cancer, ${ }^{[22]}$ cardiac and circulatory stimulation, cholesterol lowering, antitumor, antioxidant, antibacterial and anti-fungal activity. ${ }^{[11,23]}$ Lannea discolor belongs to the family of Anacardiaceae and this is also used for treatment of different ailments. ${ }^{[10,12]}$ Some of biological activities of this plant include anthelmintic, antiplasmodial, anti-cancer, nematicidal and antioxidant activity. ${ }^{[13,24]}$

The availability and concentration of phytochemicals in plants are affected by seasonal fluctuations. ${ }^{[25,26]}$ These changes in phytochemicals have been widely attributed to variations in environmental variables 
(abiotic factors) such as soil composition, responses against a variety of season specific pathogens and changes in temperature and rainfall. ${ }^{[27,28]}$ Other factors (biotic factors) such as development of the plant and plant genotype also change rapidly and these too may affect the composition of the plant parts. ${ }^{[29,30]}$ These variations seem to influence the harvest time which ensure optimum quality and yield of medicinal plant species. ${ }^{[31]}$ It is thus not surprising that the World Health Organization (WHO) recommended that parts of medicinal plants should be harvested during the appropriate season so that they should be of high quality (both raw materials and finished products). ${ }^{[32]}$

Studies have been published on the effects of seasonal variations on phytochemical composition and content of numerous medicinal plants, ${ }^{[25-30]}$ but little is known about $M$. azedarach, M.oleifera, $S$. singueana leaves, and $L$. discolor stem barks of Malawi. In addition, no comprehensive data representing optimized harvesting season for these medicinal plants exists. The present study uses HPLC to fingerprint and identify individual phenolic compounds. Variations in levels of antioxidant activity, phenolic compounds and alkaloids at different seasons of the year were investigated in plant species under study. Specifically, ferulic acid, vanillic acid, sinapic acid, (+)-catechin, rutin, quercetin, 2,4-dihydroxybenzoic acid, phenolic content, alkaloids content, flavonoids content and antioxidant activity were analyzed at different seasons of the year. The data obtained in this study provides important information that will help to determine the optimum harvesting seasons for these medicinal plants.

\section{MATERIALS AND METHODS}

\section{Chemicals}

Chemicals of HPLC and analytical grade used in this study included methanol, formic acid, acetonitrile, folin-ciocalteu phenol reagent, standards (vanillic acid, (+)-catechin, quercetin, rutin, sinapic acid, 2,4-hydroxybenzoic acid and ferulic acid) from Sigma-Aldrich Chemical Co. (USA), Gallic acid from EMD Millipore Corporation (USA), 2, 2-Diphenyl-1-Picrylhydrazyl Radical (DPPH) and 2, 4, 6-tris-2-pyridyls-triazine (TPTZ) from Sisco Research (India) and 6-hydroxy-2, 5, 7, 8-tetramethylchroman-2-carboxylic acid (Trolox) from Acros Oganics (USA).

\section{Plant materials and preparation}

Stem barks of $L$. discolor and S. singueana, M. oleifera, M. azedarach leaves were collected from northern part of Malawi, Karonga district. The samples were collected during three different seasons between the year 2019 and 2020; cool-dry (July), hot-dry (October) and hot-wet (January). The three seasons have the following temperature and rainfall patterns: cool-dry (winter), temperature 15 to $23^{\circ} \mathrm{C}$ and rainfall $1.6 \mathrm{~mm}$; hot-dry (summer), temperature 21 to $29^{\circ} \mathrm{C}$ and rainfall $3.1 \mathrm{~mm}$; hot-wet (rainy), temperature 21 to $27^{\circ} \mathrm{C}$ and rainfall $147.1 \mathrm{~mm}$ (World weather online.com). National Herbarium and Botanic Gardens (NHBG) taxonomist identified and verified medicinal plant species. The stem barks and leaves were dried by air under shed for three weeks. Domestic blender (Kenwood) was used to ground the samples to fine powder $(0.4 \mathrm{~mm})$.

\section{Sample extraction}

Extraction of phenolic compounds was achieved as previously described. ${ }^{[33-36]}$ The powdered samples $(25 \mathrm{~g})$ were soaked in $80 \% \mathrm{v} / \mathrm{v}$ methanol $(300 \mathrm{~mL})$ for $72 \mathrm{hr}$ while intermittently stirring and then filtered thereafter. Rotor evaporator (Buchi R-215, Switzerland) was used to concentrate the filtrates at $40^{\circ} \mathrm{C}$ and low pressure. Alkaloids were extracted as previously described. ${ }^{[37]}$ Semi-solid extracts $(0.1 \mathrm{~g})$ were dissolved in hydrochloric acid $(2 \mathrm{M}, 5.0 \mathrm{~mL})$, filtered and analysed. ${ }^{[36]}$

\section{Total phenolic content determination}

Total phenolic content was analysed using Folin-Ciocalteu assay. ${ }^{[36,38]}$ The effectiveness of this method is on ability of phenolic compounds to transfer electrons in a basic environment to complexes of phosphomolybdic or phosphotungstic acid which, when reduced, produce a blue colour. This colour is measured spectrophotometrically at $765 \mathrm{~nm}$ and absorption is proportional to concentration of phenolic compounds. ${ }^{[38]} \mathrm{UV}$-Vis Spectrophotometer was used to measure absorbance. Total phenolic content was quantified as milligram of gallic acid equivalents per gram of dry weight.

\section{Total flavonoid content determination}

Total flavonoids was analysed using aluminum chloride colorimetric assay ${ }^{[36,39]}$ A stable acid complex is produced when aluminium chloride reacts with keto groups or hydroxyl groups of flavonoids. This reaction produces a yellow color which can be measured spectrophotometrically at $415 \mathrm{~nm} \cdot{ }^{[39]}$ Total flavonoids content was quantified as milligram of quercetin equivalents per gram of dry weight.

\section{Total alkaloids content determination}

Total alkaloids contents were estimated spectrophotometrically using bromocresol green assay. ${ }^{[37]}$ A yellow colored complex develops when bromocresol green (BCG) and alkaloids reacts and this color is readily soluble in chloroform at $\mathrm{pH} 4.7 .{ }^{[37]}$ The filtrates were mixed with Wagner's reagent and development of brown/reddish precipitate indicated availability of alkaloids. The filtrates $(1.0 \mathrm{~mL})$ were transferred into falcon tubes in which phosphate buffer $(\mathrm{pH} 4.9,5 \mathrm{~mL})$ was added, followed by bromocresol green solution (10-4 M, $5 \mathrm{~mL}$ ) and vortexed. The complex formed was extracted using chloroform $(5 \mathrm{~mL})$. UV-Vis Spectrophotometer was used to measure absorbance at $450 \mathrm{~nm}$. Total alkaloids content was quantified as milligram of caffeine equivalent per gram of dried weight.

\section{Antioxidant activity determination (DPPH, FRAP)}

The ability of extracts to scavenge radicals was evaluated using DPPH assay. ${ }^{[36,40]}$ DPPH which is a free radical and dissolves in methanol or ethanol. The color of DPPH solution becomes lighter when antioxidant donates hydrogen atom or electron and scavenges the radical. The absorbance as a result of a change in color is measured at $517 \mathrm{~nm} \cdot{ }^{[40]}$ Results were quantified as \% DPPH.

The ability of extracts to chelate metal cations was evaluated using FRAP assay. ${ }^{[36,41]}$ This method measures the potential of antioxidants to release electrons and reduce iron(III) tripyridyl-triazine complex to Iron(II) complex in acidic medium. ${ }^{[41]}$ When antioxidants reduce ferric complex, a blue colour develops which is measured at $593 \mathrm{~nm} .{ }^{[41]}$ Ferric reducing antioxidant capacity was quantified as milligram of trolox equivalent antioxidant capacity per gram of dry weight.

\section{HPLC-DAD assay}

High performance liquid chromatography Diode Array Detector (HPLC-DAD) assay was done as previously described. ${ }^{[42]}$ With some modifications; HPLC instrument (1260 HPLC Agilent Technologies, Manchester, UK) equipped with a moel G1311C binary gradient pump, G1316A column oven and G1315D diode array detector (DAD) was used. Each standard (0.1 mg) (vanillic acid, (+)-catechin, quercetin, rutin, sinapic acid, 2,4-hydroxybenzoic acid and ferulic acid) was dissolved in $80 \%$ methanol $(100 \mathrm{~mL})$ to make $1 \mathrm{mg} / \mathrm{L}$ and used as stock solutions. Diluted extracts were filtered using $0.45 \mu \mathrm{m}$ filter membranes (Cronus PTFE). The sample $(10.0 \mu \mathrm{L})$ was injected in a $100 \mathrm{~mm} \times 4.6 \mathrm{~mm}$ Eclipse plus $3.5 \mu \mathrm{m} \mathrm{C}_{18}$ column (Agilent Technologies, Manchester, UK) for achievement of separations. This operation was conducted at $30^{\circ} \mathrm{C}$ 
using a binary mobile phase of solvent $\mathrm{A}$ ( $0.1 \%$ formic acid in water) and solvent B ( $0.1 \%$ formic acid in acetonitrile). Separation of phenolic compounds was done using a 22-min programme with the following solvent gradient: $0.01 \mathrm{~min} 5.0 \% \mathrm{~B} ; 5 \mathrm{~min} 20 \% \mathrm{~B} ; 20 \mathrm{~min} 40 \%$ B; $22 \mathrm{~min}$ $90 \% \mathrm{~B}$; and $30 \mathrm{~min} 90 \% \mathrm{~B}$. The flow rate was $0.5 \mathrm{~mL} / \mathrm{min}$. Identification of phenolic compounds was done by comparing UV spectra and retention time $\left(\mathrm{R}_{\mathrm{T}}\right)$ on chromatograms which were recorded at 280 and $302 \mathrm{~nm}$. Standard calibration curves were constructed and used for quantifying phenolic compounds in samples. Limit of detection (LOD) was calculated as $\mathrm{LOD}=y+3 S D$ and Limit of quantification (LOQ) as LOQ $=y+10 S D$, where $y$ is signal of blank and $S D$ is the standard deviation of least concentrated analyte. Recoveries of phenolic compounds were calculated after spiking the blank of the medicinal plant extracts with the reference standard. Repeatability and intermediate precision of the HPLC method was also calculated.

\section{Data Management and Analysis}

Statistical analysis was done using Paleontological Statistics Software version 3.26 (2019) and GraphPad prism version 8.3.0 (San Diego, USA). Data was presented as means \pm standard deviations $(S D)$ of analyses in triplicates. The significance between means was done at confidence level of $95 \%$.

\section{RESULTS AND DISCUSSION}

\section{Total phenolic content}

These are aromatic secondary plant metabolites with aromatic ring(s) possessing hydroxyl group(s). ${ }^{[43]}$ They exhibit different biological actions including antioxidant, anticancer, and antimicrobial, through interactions with key enzymes or antioxidant systems. ${ }^{[5,6,44]}$ The analysis of total phenolic content in medicinal plants was carried out using Folin-Ciocalteu method because the assay is both simple and sensitive ${ }^{[38]}$ Results for total phenolic content are presented in Table 1 . It was observed that total phenolic content varied significantly $(p<0.05)$ with season in all the samples. Overall TPC values ranged from $4.25 \pm 0.13 \mathrm{mg}$ GAE/g DW to 59.92 $\pm 2.32 \mathrm{mg}$ GAE/g DW. Senna singueana, M. oleifera and M. azedarach leaves exhibited highest TPC in hot-wet (rainy), followed by the cool-dry (winter) and lowest in the hot-dry (summer) season. Stem barks of L. discolor showed exceptionally highest TPC in summer followed by rainy season and lowest in the winter (Table 1). High contents of total phenolic compounds during hot-wet season could be a result of high water and low temperature stress which can stimulate the accumulation of some phenolic compounds by hydrolysis of glycosides. ${ }^{[4]}$ These results agree with the findings of Kale, ${ }^{[46]}$ who reported high total phenolic contents in Datulametel during the rainy season. ${ }^{[46]}$ The biosynthesis and accumulation of phytochemicals including phenolic compounds can be greatly influenced by internal factors such as genotype and physiological condition of the plant species. ${ }^{[4,48]}$ However, external factors including the biotic and abiotic that occur during the plant growing period may also influence the chemical composition. These external factors include feeding of seasonal insects or herbivorous animals, interaction with seasonal pathogens and diseases, the availability of light, water and temperature. ${ }^{[26,30,48-51]}$ Changes in the levels of TPC among plants may also be due to genetic responses to edaphic factors such as soil composition and nutritional stress during production of secondary metabolites. ${ }^{[52,53]}$

\section{Total flavonoids content}

Flavonoids are phytochemicals with a polyphenolic structure. ${ }^{[54]}$ They have been reported to exhibit broad biological activities including antitumor, antimicrobial, antioxidant and anticancer activities. ${ }^{[6,13,20]}$ An aluminium chloride assay was used to analyse TFC in plants due to its sensitivity and reliability. ${ }^{[39]}$ The flavonoids contents of each plant species varied according to seasonal changes with all the samples exhibiting high contents in the hot-wet season as presented in Table 1. S. singueana leaves showed high contents of TFC $(16.97 \pm 0.23 \mathrm{mg}$ QE/g DW). TFC decreased significantly $(p<0.05)$ in the following order: $S$. singueana $>$ L. discolor $>M$. oleifera $>M$. azedarach. Lannea discolor stem barks and $M$. azedarach leaves contained low flavonoid content during cool-dry season while $S$. singueana and $M$. oleifera leaves contained low content during hot-dry season. Lannea discolor stem barks showed low amounts of flavonoids $(0.15 \pm 0.01 \mathrm{mg} \mathrm{QE} / \mathrm{g} \mathrm{DW})$ despite exhibiting high level of TPC in cool-dry season (Table 1). The changes in amounts of TFC might be because of the same variables that have been linked to affect TPC, because flavonoids are one of the subgroups of phenolic compounds. ${ }^{[26,30,48-51]}$ These high flavonoid contents reported here during the hot-wet season are in agreement with previous work, which indicated that total flavonoids content were high during the rainy season in Ocimum sanctum. ${ }^{[55]}$

\section{Total alkaloids content}

Alkaloids are complex heterocyclic nitrogen compounds of natural origin with a basic character found in plant species. ${ }^{[56]}$ The biological actions of some alkaloids has resulted to investigations as pharmaceuticals, which have proven to be effective. ${ }^{[57,58]} \mathrm{A}$ Bromocresol green assay was used to analyse TAC in plants as the method is both simple and efficient. ${ }^{[37]}$ Total alkaloids content varied significantly $(p<0.05)$ and values ranged from $98.2 \pm 2.2 \mathrm{mg} \mathrm{CE} / \mathrm{g} \mathrm{DW}$ to $295.1 \pm 3.8 \mathrm{mg} \mathrm{CE} / \mathrm{g} \mathrm{DW}$. The contents of alkaloids, as did the total phenolic content and flavonoids, varied widely according to season (Table 1). Lannea discolor contained high amounts of alkaloids in summer and low in winter. Leaves of S. singueana, M. oleifera and $M$. azedarach contained high alkaloids contents during the rainy season and low in the winter. High alkaloids contents in the rainy season in L. discolor could result from a decrease in biomass production or temperature stress which can result in changes in the biochemistry of medicinal plant species. ${ }^{[49]}$ Temperature stress affects biosynthetic pathways in the development of alkaloids, by providing precursors from the primary metabolism which elevate production of alkaloids to counteract oxidative stress. ${ }^{[28,49]}$ Similar observations of high alkaloid contents during the rainy season in medicinal plants have been previously reported. ${ }^{[46]}$ The results are also in agreement with findings of other researchers in different plant species. For example, the contents of alkaloids in B. prionitis, B. diffusa, C. colocynthis and G. tenax were higher in summer compared to winter and the rainy season. ${ }^{[27]}$ High contents of phytochemicals during the hot-wet season in leaves of S. singueana, $M$. oleifera and $M$. azedarach may be associated with an increase in soil salinity due to anthropogenic activities or transfer of minerals from rocks into soils from runoff. In plant cells, these phytochemicals serve as an osmolyte through decreasing stresses that arise from the salinity stress in growth conditions of plant species by increasing their amounts of production. ${ }^{[49,59]}$ Plant samples were collected in three different seasons which are characterized by variable average temperatures and rainfall patterns. These abiotic factors have previously been suggested to affect the availability and quantity of phytochemicals in other plants. ${ }^{[45,46,50]}$

\section{Antioxidant Activity}

Antioxidants are phytochemicals that prevent or inhibit the oxidation of some molecules, such as DNA, by scavenging radicals and mitigating stress. ${ }^{[44,54,57]}$ Antioxidant activity was analyzed using easy and rapid methods (FRAP and DPPH). ${ }^{[40,41]}$ Results showed significant variation of antioxidant activity with season (Table 1 ). For barks of $L$. discolor, maximum values were observed in summer. For S. singueana, M. oleifera and M. Azedarach leaves, highest antioxidant values were found in samples from the rainy season. Antioxidant activity results were proportional to the TPC and TAC described earlier. The antioxidant actions 
Table 1: Total phenolic content (mg GAE/g DW), Total flavonoids content (mg QE/g DW), Total alkaloids content (mg CE/g DW) and antioxidant activity (FRAP (mg TEAC/g DW); DPPH (\%)) of medicinal plant species.

\begin{tabular}{|c|c|c|c|c|c|c|c|c|c|c|c|c|c|c|c|}
\hline & \multicolumn{5}{|c|}{ Cool-Dry Season (winter) } & \multicolumn{5}{|c|}{ Hot-Dry Season (summer) } & \multicolumn{5}{|c|}{ Hot-Wet Season (rainy) } \\
\hline & TPC* & $\mathrm{TFC}^{*}$ & TAC & FRAP* & $\mathrm{DPPH}^{*}$ & TPC & TFC & TAC & FARP & DPPH & TPC & TFC & TAC & FRAP & DPPH \\
\hline \multirow[t]{3}{*}{ Ss } & 15.82 & 7.37 & 106.2 & 124.4 & 67.2 & 7.81 & 4.46 & 112.1 & 101.3 & 56.5 & 44.51 & 16.97 & 212.1 & 166.8 & 69.5 \\
\hline & \pm & \pm & \pm & \pm & \pm & \pm & \pm & \pm & \pm & \pm & \pm & \pm & \pm & \pm & \pm \\
\hline & $1.01^{\mathrm{b}}$ & $0.1^{\mathrm{a}}$ & $4.61^{\mathrm{d}}$ & $0.91^{\mathrm{b}}$ & $1.42^{\mathrm{b}}$ & $1.22^{\mathrm{b}}$ & $1.85^{\mathrm{a}}$ & $7.04^{c}$ & $2.11^{\mathrm{b}}$ & $1.12^{\mathrm{b}}$ & $2.43^{\mathrm{b}}$ & $1.23^{\mathrm{a}}$ & $6.89^{\mathrm{a}}$ & $4.23^{\mathrm{b}}$ & $3.14^{\mathrm{b}}$ \\
\hline \multirow[t]{3}{*}{$L d$} & 27.64 & 0.15 & 176 & 166.3 & 89.1 & 59.92 & 4.12 & 295.1 & 186.4 & 95.22 & 53.78 & 16.68 & 215.1 & 174.7 & 90.2 \\
\hline & \pm & \pm & \pm & \pm & \pm & \pm & \pm & \pm & \pm & \pm & \pm & \pm & \pm & \pm & \pm \\
\hline & $2.5^{\mathrm{a}}$ & $0.01^{\mathrm{d}}$ & $2.23^{\mathrm{a}}$ & $1.65^{\mathrm{a}}$ & $1.18^{\mathrm{a}}$ & $3.21^{\mathrm{a}}$ & $0.65^{\mathrm{a}}$ & $9.33^{\mathrm{a}}$ & $3.37^{\mathrm{a}}$ & $3.44^{\mathrm{a}}$ & $5.13^{\mathrm{a}}$ & $0.11^{\mathrm{a}}$ & $12.45^{\mathrm{a}}$ & $3.94^{\mathrm{a}}$ & $5.43^{\mathrm{a}}$ \\
\hline \multirow[t]{3}{*}{ Mo } & 12.33 & 4.83 & 115 & 85.5 & 57.9 & 5.14 & 3.49 & 98.22 & 80.31 & 43.62 & 26.06 & 12.34 & 128.2 & 126.4 & 65.2 \\
\hline & \pm & \pm & \pm & \pm & \pm & \pm & \pm & \pm & \pm & \pm & \pm & \pm & \pm & \pm & \pm \\
\hline & $1.32^{\mathrm{c}}$ & $0.11^{\mathrm{b}}$ & $7.33^{c}$ & $0.96^{c}$ & $2.81^{c}$ & $1.32^{\mathrm{c}}$ & $0.32^{\mathrm{b}}$ & $5.53^{c}$ & $6.49^{c}$ & $2.14^{\mathrm{c}}$ & $1.32^{\mathrm{c}}$ & $1.32^{\mathrm{b}}$ & $3.42^{c}$ & $5.61^{c}$ & $2.58^{\mathrm{c}}$ \\
\hline \multirow[t]{3}{*}{$M a$} & 7.83 & 0.53 & 120 & 68.5 & 42.7 & 4.25 & 1.87 & 126.3 & 79.92 & 48.91 & 22.73 & 9.23 & 148.3 & 115.3 & 54.9 \\
\hline & \pm & \pm & \pm & \pm & \pm & \pm & \pm & \pm & \pm & \pm & \pm & \pm & \pm & \pm & \pm \\
\hline & $0.01^{\mathrm{d}}$ & $0.02^{c}$ & $9.33^{\mathrm{b}}$ & $1.72^{\mathrm{d}}$ & $0.18^{\mathrm{d}}$ & $0.11^{\mathrm{c}}$ & $0.01^{c}$ & $10.3^{\mathrm{b}}$ & $2.31^{c}$ & $4.59^{c}$ & $2.32^{\mathrm{d}}$ & $0.01^{c}$ & $17.55^{\mathrm{b}}$ & $2.37^{\mathrm{d}}$ & $1.17^{\mathrm{d}}$ \\
\hline
\end{tabular}

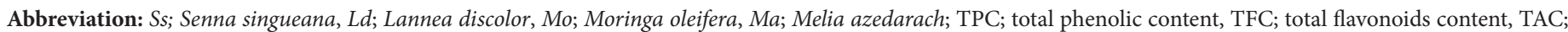

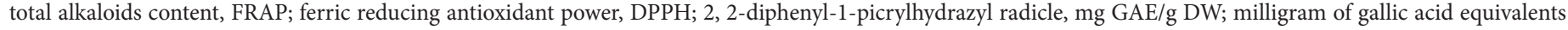

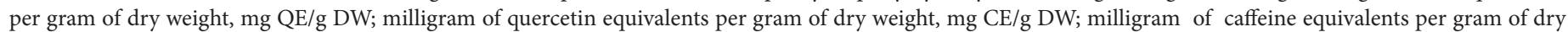

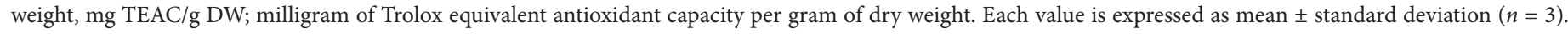

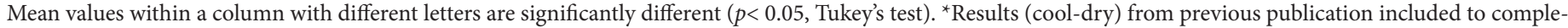
ment three seasons. ${ }^{[36]}$

Table 2: Correlation coefficients between antioxidant activity and variables.

\begin{tabular}{ccccccc}
\hline & \multicolumn{2}{c}{$\begin{array}{c}\text { Cool-Dry Season } \\
\text { (winter) }\end{array}$} & \multicolumn{2}{c}{$\begin{array}{c}\text { Hot-Dry Season } \\
\text { (summer) }\end{array}$} & \multicolumn{2}{c}{$\begin{array}{c}\text { Hot-Wet-Season } \\
\text { (rainy) }\end{array}$} \\
\hline & FRAP & DPPH & FRAP & DPPH & FRAP & DPPH \\
TPC & $0.9764^{*}$ & $0.9882^{*}$ & $0.9897^{*}$ & $0.9824^{*}$ & $0.9873^{*}$ & 0.9136 \\
TFC & -0.0896 & -0.0803 & 0.5043 & 0.4565 & $0.9501^{*}$ & 0.7544 \\
TAC & 0.7313 & 0.7490 & $0.9728^{*}$ & $0.9778^{*}$ & 0.9389 & 0.7207 \\
FRAP & $1^{*}$ & $0.9818^{*}$ & $1^{*}$ & $0.9956^{*}$ & $1^{*}$ & 0.8636 \\
& & $0.9640^{* *}$ & & $0.9913^{* *}$ & & $0.7458^{* *}$ \\
\hline
\end{tabular}

Abbreviations: TPC; totoal phenolic content, TFC; totoal flavonoids content, TAC; totoal alkaloids content, DPPH; 2, 2-diphenyl-1-picrylhydrazyl radical, FRAP; ferric reducing antioxidant power. $p<0.05\left(^{*}\right)$, linear regression coefficients $\left.{ }^{* *}\right)$.

of these medicinal plant species could be as a result of the presence of phytochemicals such as phenolic compounds and alkaloids. ${ }^{[53-56]}$ In contrast, the effect of seasonal changes on antioxidant activity of Ginkgo biloba was highest in the autumn. ${ }^{[60]}$ In another study, seasonal changes on antioxidant activity of Nothapodytes nimmoniana were found to be high in winter ${ }^{[61]}$ Production of phytochemicals and antioxidant activity, in respect to environmental stress during different seasons, have been linked to defense mechanisms. ${ }^{[6,7,29-32,49,54]}$

\section{Correlation between antioxidant activity and TPC, TFC and TAP}

Linear regression and Pearson's correlation analyses were performed to validate the two assays used to analyze total antioxidant activity of four plant species under study. The Pearson's $r$ and linearity $\left(r^{2}\right)$ are presented in Table 2. FRAP and DPPH were significantly $(p<0.05)$ and positively correlated. The findings demonstrate the suitability and reliability of the two assay methods as vehicles for evaluating total antioxidant capabilities of plant extracts. Amounts of phenolic compounds and alkaloids of all the medicinal plant species under study exhibited positive correlations with antioxidant capacity (FRAP and DPPH) throughout the seasons (Table 2). Positive correlations which were significant $(p<0.05)$ were also observed between TPC and FRAP. Flavonoids showed a positive correlation with antioxidant activity except during cool-dry season, in which it exhibited a non-significant negative correlation $(-0.0896$ and -0.0803 for FRAP and DPPH respectively). Most flavonoids are generally present as glycosides in plants of which they are usually conjugated with glucose. Previous studies indicate that glycosylated flavonoids have lower antioxidant capacity than their corresponding aglycones. ${ }^{[62,63]}$ Generally, the two assays showed consistent results with the seasonal variations of total phenolic compounds and total alkaloids. This demonstrates that higher antioxidant activity of samples, especially those collected in summer and rainy seasons, maybe attributed to higher total phenolic and alkaloids contents. Phytochemicals such as phenolic compounds and alkaloids significantly contribute to antioxidant activity of selected medicinal plants. ${ }^{[64,65]}$ This stronger correlation between antioxidant activity and phytochemicals observed in the present study supports the findings of literature. ${ }^{[64-69]}$

\section{Phenolic compounds identification and quantification}

HPLC fingerprints of standard phenolic compounds can be used as a baseline for comparison when analyzing unknown compounds responsible for therapeutic activities in plants. ${ }^{[34,40]}$ Therefore, to identify individual phenolic compounds responsible for antioxidant properties, HPLC was used because the technique is extremely quick and efficient. ${ }^{[42]}$ Seven standard phenolic compounds were used for peak identification and the chromatography parameters are presented in Table 3. Except quercetin, values for compounds in all samples were satisfactory. Five (5) of phenolic compounds including (+)-catechin, sinapic acid, 2,4-dihydroxybenzoic acid, quercetin and ferulic acid were observed in leaves of $S$. singueana extracts using HPLC- DAD (Figure 1, Table 4). Similar observations have been reported about the availability of phenolic compounds in S. singueana extracts. ${ }^{[70,71]}$ The presence of $(+)$-catechin, quercetin, 2,4-dihydroxybenzoic acid, ferulic acid, and sinapic acid in S. singueana 
Table 3: Chromatography parameters of standard compounds used for peak identification.

\begin{tabular}{|c|c|c|c|c|c|c|c|c|c|c|c|c|c|}
\hline \multirow[t]{2}{*}{ Standard } & \multirow{2}{*}{$\begin{array}{c}\mathrm{R}_{\mathrm{T}} \\
\text { (min) }\end{array}$} & \multirow{2}{*}{$\begin{array}{l}\text { Wavelength } \\
(\mathrm{nm})\end{array}$} & \multirow{2}{*}{$\begin{array}{l}\text { LOD } \\
(\mu \mathrm{g} / \mathrm{m})\end{array}$} & \multirow{2}{*}{$\begin{array}{l}\text { LOQ } \\
(\mu \mathrm{g} / \\
\mathrm{mL})\end{array}$} & \multirow{2}{*}{$\begin{array}{c}\text { Linearity } \\
\left(r^{2}\right)\end{array}$} & \multirow{2}{*}{$\begin{array}{c}\text { Recovery } \\
\text { (\%) }\end{array}$} & \multicolumn{4}{|c|}{ Repeatability } & \multicolumn{3}{|c|}{ Intermediate Precision } \\
\hline & & & & & & & 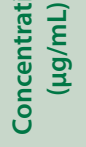 & $\times \begin{array}{l}\bar{m} \\
\| \\
\Xi\end{array}$ & ڤิ & $\begin{array}{l}\circ \\
\stackrel{\circ}{x}\end{array}$ & $\times \begin{array}{l}m \\
\| \\
\Xi\end{array}$ & ڤิ & $\begin{array}{l}\stackrel{0}{0} \\
\text { ڤิ }\end{array}$ \\
\hline \multirow[t]{4}{*}{$(+)-$ catechin } & 8.16 & 280 & 1.99 & 2.00 & 0.9965 & $95.01 \pm 5.1$ & 40 & 39.32 & 0.324 & 0.8240 & 41.22 & 1.4521 & 1.7542 \\
\hline & & & & & & & 50 & 46.82 & 0.4933 & 1.053 & 48.3 & 0.7365 & 1.114 \\
\hline & & & & & & & 100 & 97.72 & 1.083 & 1.108 & 98.88 & 2.167 & 0.2191 \\
\hline & & & & & & & 150 & 146.9 & 0.4195 & 0.2854 & 145.21 & 0.1132 & 0.1761 \\
\hline \multirow[t]{4}{*}{ Rutin } & 9.23 & 280 & 0.03 & 0.10 & 0.9940 & $82.10 \pm 0.4$ & 40 & 34.54 & 0.1957 & 0.5666 & 38.76 & 1.5343 & 0.2534 \\
\hline & & & & & & & 50 & 52.69 & 0.1596 & 0.3029 & 51.55 & 2.8632 & 0.6521 \\
\hline & & & & & & & 100 & 103.4 & 3.218 & 3.113 & 104.23 & 4.3327 & 1.3425 \\
\hline & & & & & & & 150 & 144.1 & 3.406 & 2.365 & 147.32 & 0.2763 & 0.4628 \\
\hline \multirow[t]{4}{*}{ Vanillic acid } & 9.77 & 302 & 0.38 & 1.28 & 0.9972 & $89.97 \pm 7.2$ & 40 & 38.44 & 0.1218 & 0.3169 & 42.31 & 2.7132 & 1.6362 \\
\hline & & & & & & & 50 & 49.79 & 0.0223 & 0.0449 & 52.56 & 3.127 & 2.3287 \\
\hline & & & & & & & 100 & 103.8 & 1.346 & 1.296 & 99.21 & 0.0721 & 3.0517 \\
\hline & & & & & & & 150 & 147.9 & 0.2021 & 0.1366 & 153.63 & 1.7632 & 0.1001 \\
\hline \multirow{4}{*}{$\begin{array}{c}\text { 2,4-dihydroxy } \\
\text { benzoic acid }\end{array}$} & 10.62 & 302 & 0.24 & 0.80 & 0.9909 & $115.0 \pm 3.5$ & 40 & 38.7001 & 0.05766 & 0.14898 & 43. 911 & 1.4381 & 4.0618 \\
\hline & & & & & & & 50 & 47.8631 & 0.0656 & 0.13705 & 49.041 & 0.1298 & 2.9172 \\
\hline & & & & & & & 100 & 107.1 & 0.4916 & 0.4589 & 110.14 & 3.854 & 0.6652 \\
\hline & & & & & & & 150 & 146.3 & 0.2107 & 0.144 & 152.12 & 2.016 & 1.635 \\
\hline \multirow[t]{4}{*}{ Sinapic acid } & 11.92 & 280 & 0.26 & 0.86 & 0.9944 & $88.21 \pm 4.2$ & 40 & 37.9 & 0.0342 & 0.0902 & 42.142 & 1.436 & 1.3141 \\
\hline & & & & & & & 50 & 50.61 & 2.106 & 4.16 & 51.717 & 4.014 & 3.615 \\
\hline & & & & & & & 100 & 105.3 & 0.182 & 0.1728 & 99.612 & 1.7351 & 1.631 \\
\hline & & & & & & & 150 & 146.8 & 4.402 & 2.999 & 153.72 & 3.128 & 1.0301 \\
\hline \multirow[t]{4}{*}{ Ferulic acid } & 12.47 & 302 & 0.08 & 2.86 & 1.0000 & $73.59 \pm 1.6$ & 40 & 40.04 & 0.8992 & 2.246 & 41.021 & 2.873 & 1.2342 \\
\hline & & & & & & & 50 & - & - & - & - & - & - \\
\hline & & & & & & & 100 & - & - & - & 101.32 & 2.605 & 7.862 \\
\hline & & & & & & & 150 & 149.9 & 0.7654 & 0.5106 & 147.16 & 0.2431 & 1.4352 \\
\hline Quercetin & 18.05 & 302 & - & - & 0.9989 & $71.40 \pm 0.1$ & 40 & 38.61 & 0.0342 & 0.0887 & 44.12 & 1.23 & 2.103 \\
\hline \multirow[t]{3}{*}{ Dehydrate } & & & & & & & 50 & 50.46 & 0.0401 & 0.0794 & 48.53 & 3.651 & 1.641 \\
\hline & & & & & & & 100 & 102.1 & 0.0837 & 0.0819 & 96.53 & 0.725 & 0.171 \\
\hline & & & & & & & 150 & 148.8 & 0.058 & 0.039 & 154.51 & 1.634 & 0.01 \\
\hline
\end{tabular}

Abbreviations: X; mean concentration, $\mathrm{R}_{\mathrm{T}}$; Retention time, SD; Standard deviation, LOQ; Limit of quantification, RSD\%; Relative standard deviation, $\mathrm{n}$; number of replicates, LOD; Limit of detection,

varied significantly $(p<0.05)$ with season (Figure 1 , Table 4$)$. It was observed that ferulic acid and (+)-catechin were present in only two seasons; winter and rainy seasons, while quercetin was present only during the rainy season. Vanilic acid and rutin were not detected throughout seasons. Sinapic acid and 2, 4-dihydroxybenzoic acid were the predominant compounds observed across seasons and their concentrations increased significantly $(p<0.05)$ in the following order: summer $<$ winter $<$ rainy season. Watoo et al. ${ }^{[45]}$ hypothesized that water stress during the rainy season can stimulate the accumulation of some phenolic compounds through hydrolysis of phenolic glycosides. ${ }^{[45]}$ In another study, quercetin concentration increased significantly as a result of temperature and water stress response in $H$. brasiliense. ${ }^{[72]}$ In contrast, Gray et al. ${ }^{[73]}$ Observed an increase in concentration of quercetin in H. perforatum plants which were subjected to drought stress. ${ }^{[73]}$ These findings suggest that plants have developed different defense systems to mitigate the oxidative effects caused by different stresses including overproduction of antioxidant compounds which terminates oxidative chain reactions. ${ }^{[59,74,75]}$

In the barks of $L$. discolor extracts, four phenolic compounds, ferulic acid, vanillic acid, 2,4-dihydroxybenzoic acid and (+)-catechin were identified (Table 4). Seasonal variations affected the presence of phenolic compounds in extracts of $L$. discolor. For example, vanilic acid was a predominant compound as it was detected in all seasons, while ferulic acid and 2,4-dihydroxybenzoic acid were detected during winter only. $(+)$-catechin was present in summer and rainy seasons. On the other hand, sinapic acid and rutin were not detected throughout the seasons. Such variations may be due to differences in the control mechanisms of the compound biosynthetic pathway, alteration of substrate availability and degradation of the compounds at different seasons. ${ }^{[76]}$ In the findings of another study, variation in the development and accumulation of 

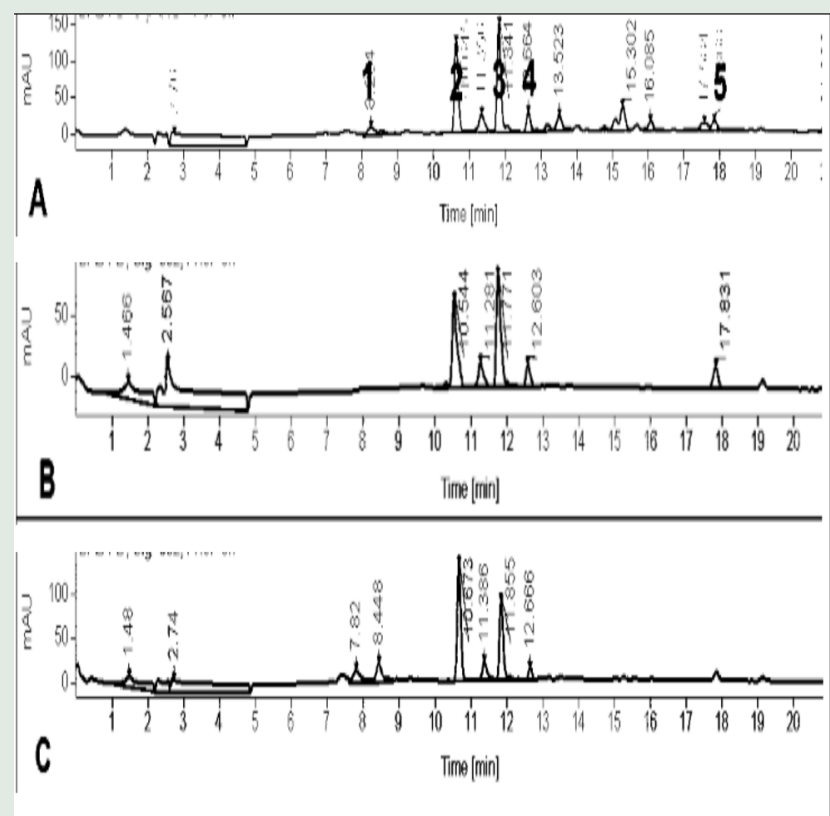

Figure 1: HPLC-DAD chromatograms of phenolic compounds present in senna singueana extracts during different seasons. (A) hot-wet season (B) hot-dry season (C) cool-dry season. Peaks: 1: (+)-catechin; 2: 2,4-dihydroxybenzoic acid; 3: Sinapic acid; 4: Ferulic acid; 5: quercetin. phenolic compounds were associated with defense processes of the plants. ${ }^{[49,50]}$ It has been reported that ferulic acid increases the strength of plant cell walls by covalently linking with lignin and other biopolymers, ${ }^{[77]}$ while benzoic acids provide defenses against antimicrobial activities of reproductive tissues ${ }^{[78]}$ Catechins contribute to defence in plants by scavenging reactive oxygen species and diminishing oxidative stress. ${ }^{[79]}$

In $M$. azedarach extracts, four phenolic compounds including 2,4-dihydroxybenzoic acid, (+)-catechin, vanillic acid and sinapic acid were observed (Table 4). Similar compounds in leaves of $M$. azedarach have been reported by other researchers. ${ }^{[80-82]}$ The presence and levels of observed phenolic compounds varied significantly with season just like the other three medicinal plants described earlier. In contrast to leaves of Moringa oleifera and barks of $L$. discolor, a different phenolic compound, 2,4-dihydroxybenzoic acid was the predominant compound in $M$. azedarach. The concentration of 2,4-dihydroxybenzoic acid increased significantly $(p<0.05)$ with season in the following order; summer $<$ winter $<$ rainy season. $(+)$-Catechin was present in two seasons only: summer and winter seasons. The concentration of $(+)$-catechin was significantly higher $(p<0.05)$ in summer than in winter (Table 4$)$. Vanillic acid was detected during winter while Sinapic acid was present across all seasons. Ferulic acid, rutin and quercetin were not detected throughout the seasons. The observations are in line with those suggested by Cezarotto et al. ${ }^{[83]}$ Who observed variation of phenolic compounds in Vacciniumashei leaves due to seasonal changes. ${ }^{[83]}$

Finally, in the leaf extract of $M$. oleifera, five phenolic compounds including vanillic acid, ferulic acid, 2,4-dihydroxybenzoic acid, (+)

Table 4: Amounts of phenolic compounds in medicinal plants extracts using HPLC -DAD (mg/100 g DW dry weight).

\begin{tabular}{|c|c|c|c|c|c|c|c|c|c|c|c|c|}
\hline \multirow[t]{2}{*}{ Compound/Herb } & \multicolumn{4}{|c|}{ Hot-Wet Season (rainy) } & \multicolumn{4}{|c|}{ Hot-Dry Season (summer) } & \multicolumn{4}{|c|}{ Cool-Dry Season (winter) } \\
\hline & Ss & $L d$ & Mo & $M a$ & Ss & $L d$ & Mo & $M a$ & Ss & $L d$ & Mo & $M a$ \\
\hline \multirow[t]{3}{*}{ (+) -Catechin, } & 22.76 & 27.95 & nd & nd & nd & 31.16 & 202.55 & 141.70 & 33.28 & nd & 39.70 & 80.36 \\
\hline & \pm & \pm & & & & \pm & \pm & \pm & \pm & & \pm & \pm \\
\hline & $0.01^{\mathrm{e}}$ & $6.21^{\mathrm{a}}$ & & & & $0.24^{\mathrm{b}}$ & $20.54^{\mathrm{a}}$ & $29.04^{a}$ & $10.10^{\mathrm{a}}$ & & $5.96^{\mathrm{a}}$ & $13.63^{\mathrm{a}}$ \\
\hline \multirow[t]{3}{*}{ Rutin } & nd & nd & nd & nd & nd & 19.15 & nd & nd & nd & nd & nd & nd \\
\hline & & & & & & \pm & & & & & & \\
\hline & & & & & & $0.81^{\mathrm{a}}$ & & & & & & \\
\hline \multirow[t]{3}{*}{ Vanillic acid } & nd & 36.56 & 24.56 & nd & nd & 23.69 & nd & nd & nd & 49.26 & nd & 6.86 \\
\hline & & \pm & \pm & & & \pm & & & & \pm & & \pm \\
\hline & & $0.55^{\mathrm{b}}$ & $0.03^{c}$ & & & $0.01^{\mathrm{c}}$ & & & & $0.02^{c}$ & & $0.01^{c}$ \\
\hline \multirow{3}{*}{$\begin{array}{l}2,4 \text { dihydroxy } \\
\text { benzoic acid, }\end{array}$} & 66.72 & nd & nd & 93.34 & 49.29 & nd & 18.24 & 26.25 & 64.73 & 36.03 & 13.53 & 41.53 \\
\hline & \pm & & & \pm & \pm & & \pm & \pm & \pm & \pm & \pm & \pm \\
\hline & $0.32^{c}$ & & & $0.13^{\mathrm{b}}$ & $1.28^{\mathrm{a}}$ & & $0.09^{\mathrm{d}}$ & $1.85^{\mathrm{b}}$ & $0.10^{\mathrm{b}}$ & $0.07^{\mathrm{b}}$ & $1.08^{\mathrm{b}}$ & $0.07^{\mathrm{b}}$ \\
\hline \multirow[t]{3}{*}{ Sinapic acid } & 7.12 & nd & 4.53 & 5.16 & 4.62 & uq & 7.56 & ud & 5.24 & nd & 8.34 & 1.59 \\
\hline & \pm & & \pm & \pm & \pm & & \pm & & \pm & & \pm & \pm \\
\hline & $0.03^{\mathrm{d}}$ & & $0.16^{\mathrm{a}}$ & $0.17^{\mathrm{a}}$ & $0.02^{\mathrm{b}}$ & & $0.19^{c}$ & & $0.01^{\mathrm{d}}$ & & $0.00^{\mathrm{d}}$ & $0.01^{c}$ \\
\hline \multirow[t]{3}{*}{ Ferulic acid } & 264.0 & nd & 104.61 & nd & nd & nd & 91.25 & nd & 140.34 & 1498.6 & 140.02 & nd \\
\hline & \pm & & \pm & & & & \pm & & \pm & \pm & \pm & \\
\hline & $2.84^{\mathrm{a}}$ & & $0.14^{\mathrm{b}}$ & & & & $0.52^{\mathrm{b}}$ & & $0.06^{c}$ & $0.11^{\mathrm{a}}$ & $0.72^{c}$ & \\
\hline \multirow[t]{3}{*}{ Quercetin } & 16.69 & nd & nd & nd & nd & nd & nd & nd & nd & nd & nd & nd \\
\hline & \pm & & & & & & & & & & & \\
\hline & $0.81^{\mathrm{b}}$ & & & & & & & & & & & \\
\hline
\end{tabular}

Abbreviations: DW: Dry weight; Ss: Senna singueana; Ld: Lannea discolor; Mo: Moringa oleifera; Ma: Melia azedarach; nd: not detected; ud: under the limit of detection; uq: under limit of quantification. Data are means \pm standard deviation $(n=3)$. The values which do not share superscript letters within a column indicate significant differences $(p<0.05$, Tukey's test) 


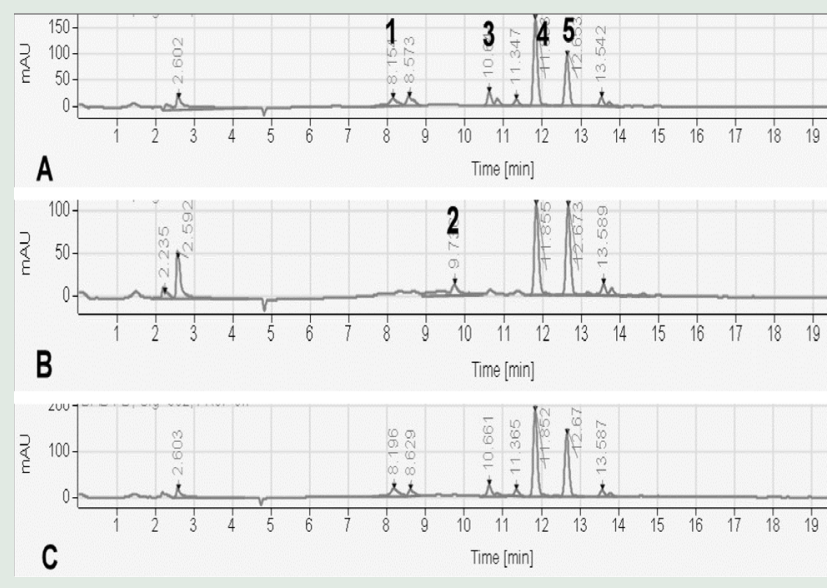

Figure 2: HPLC-DAD chromatograms of phenolic compounds present in Moringa oleifera extracts during different seasons. (A) hot-dry season (B) hot-wet season (C) cool-dry season. Peaks: 1: (+)-catechin; 2: Vanillic acid; 3: 2,4-dihydroxybenzoic acid; 4: Sinapic acid; 5: Ferulic acid.

-catechin, sinapic acid and were observed (Figure 2, Table 4). The availability of phenolic compounds in M. oleifera has been reported by several other researchers. ${ }^{[84-87]}$ These phenolic compounds also varied during different seasons. (+)-Catechin was present in two seasons only: summer and winter. The concentration of $(+)$-catechin was significantly higher $(p<0.05)$ in summer as compared to winter (Table 4$)$. Vanilic acid was detected in the rainy season only, while 2,4-dihydroxybenzoic acid was present in summer and in winter. Ferulic acid and sinapic acid were predominant compounds in extracts of $M$. oleifera. The concentrations significantly increased $(p<0.05)$ in the following order: rainy season $<$ summer $<$ winter for sinapic acid; and summer $<$ rainy season $<$ winter for ferulic acid. Different environmental conditions, leaf maturity stage and reactions against seasonal pests may have contributed to the variations of phenolic compounds in the leaves of M. oleifera extracts, as observed by Ndhlala et al. ${ }^{[88]}$ Similarly, seasonal variations of phenolic profiles in extracts of Juglanssigillata Dode were also observed by Binbin et al. ${ }^{[89]}$ Changes in environmental conditions during different seasons and the genetic predisposition of plant species under study may contribute to the variations of compounds. ${ }^{[90]}$ The present findings indicate that plant chemical composition is influenced by seasonal changes. A specific compound may be present in one or two seasons and not available in the other. Thus, the quality of fresh or derived products is likely to be dependent upon harvesting season which in turn affects pharmacological properties, as described by Costa et al. ${ }^{[91]}$

\section{CONCLUSION}

The present study has revealed some important phytochemicals in Malawian medicinal plants that may be useful in the management of several disease conditions, including cancer. In addition, it has shown that the availability and levels of phytochemicals are largely influenced by season. Barks of $L$. discolor exhibited high levels of (+)-catechin, rutin, amounts of total phenolic compounds, total flavonoids, total alkaloids and antioxidant activity during hot-dry season (summer). Leaves of $S$. singueana showed high levels of sinapic acid, ferulic acid and 2,4-dihydroxybenzoic acid during hot-wet season. S. singueana, $M$. oleifera and $M$. azedarach leaves showed significantly $(p<0.05)$ high amounts of total phenolic compounds, total flavonoids, total alkaloids and antioxidant activity in the hot-wet season (rainy). Based on the results we conclude that the hot-dry season is optimum for harvesting barks of $L$. discolor, while the hot-wet season is optimum for harvesting, M. oleifera, M. azedarach and S. singueana leaves for pharmacological use. Further studies including in vivo antioxidant activity and characterization of bioactive compounds are recommended for therapeutic use.

\section{ACKNOWLEDGEMENT}

Authors would like to thank African Centre of Excellence in Public Health and Herbal Medicine (ACEPHEM) for funding this study. It is a continuation of previous publication in Scientific African. Authors appreciate Dr Erika Shilling (University of Leeds, United Kingdom) and Dr Islamiyat Bolarinwa (Ladoke Akinkola University of Technology, Nigeria) for editing the final draft of the article.

\section{CONFLICT OF INTEREST}

The authors declare no conflicts of interest.

\section{Financial support and sponsorship}

African Centre of Excellence in Public Health and Herbal Medicine.

\section{ABBREVIATIONS}

DPPH: 2,2-diphenyl-1-picrylhydrazyl; TFC: Total Flavonoids Content; TAC: Total Alkaloids Content; FRAP: Ferric Reducing Antioxidant Power; HPLC - DAD:High performance liquid chromatography diode array detector; TPC: Total Phenolic Content; AA: Antioxidant Activity.

\section{REFERENCES}

1. World Health Organization. WHO traditional medicine strategy: 2014-2023. World Health Organization, Geneva, 2013.

2. Maliwichi-Nyirenda CP, Maliwichi LL. Medicinal plants used to induce labour and traditional techniques used in determination of onset of labour in pregnant women in Malawi: A case study of Mulanje District. Journal of Medicinal Plants Research 2010; 4 (24): 2609-2614.

3. Chisala SE. Protecting traditional healing practices in Malawi. Are there practices to be learnt in South Africa? PhD. Thesis, Faculty of Law, University of Ghana, Accra, Ghana. (2005)

4. Jaganath IB, Crozier A. Plant phenolics and human health: Biochemistry, nutrition and pharmacology, $1^{\text {st }}$ edition, John Whiley and Sons: New Jersey. 2010; p. 1-38.

5. Qurishi Y, Hamid A, Zargar MA, Singh SK, Saxena AK. Potential role of natural molecules in health and disease: Importance of boswellic acid. J. Med. Plants Res. 2010; (4): 2778-2785

6. Shashank K, Pandey AK. Chemistry and Biological Activities of Flavonoids: An Overview. University of Allahabad, India. Sci. World J. 2013; 28: 11-12.

7. Beaudoin GAW, Facchini PJ. Benzylisoquinoline alkaloid biosynthesis in opium poppy. Planta. 2014; 240:19-32.

8. Shawa IT, Msefula C, Mponda J. et al. Antibacterial effects of aqueous extracts of musa paradisiaca, ziziphus mucronata and senna singueana plants of Malawi. Int. J. Health Sci. Res. 2016; 6(2):200-207.

9. Chikowe I, Mnyenyembe B, Jere S, Andrew G. Mtewa AG, John Mponda J Lampiao F. An Ethnomedicinal Survey of Indigenous Knowledge on Medicinal Plants in the Traditional Authority Chikowi in Zomba, Malawi. Current Traditional Med.2020; 6 (3):225-241.

10. Bundschuh TV, Hahn K, Wittig R. The medicinal plants of the woodlands in northern Malawi (Karonga district). Flora et VegetatioSudano-Sambesica. 2011; $14: 3-8$.

11. Kasolo JN, Bimenya GS, Ojok L, Ochieng J, Ogwal-Okeng JW. Phytochemicals and uses of Moringa oleifera leaves in Ugandan rural communities. J. Med. Plants Res. 2010; 4 (9).

12. Nyoni M, Muzemu S, Chinheya C, Mushayabasa T, Ncube B. Screening Indigenous Nematicidal Plants in Zimbabwe Against Meloidogyne javanica. Paper Presented at a Conference; 2015 July 14-16; Elephant Hills Resort Victoria Fallls, Zimbabwe; 2015.

13. Chakuma N, Chipurura B, Muchuweti M, Chitindingu K, Bhebhe M, Chagonda L. Total phenolic content, free radical scavenging and antioxidant potentia of Lannea discolor (Sond.) Engl bark and root extracts. J. Bio. Act. Pro. Nat. 2015;5(1):71-77 
14. Gebrelibanos, M. In vitro Erythrocyte Haemolysis Inhibition Properties of Senna singueana Extracts. Momona Ethiopian J. Sci. 2012; 4 (2), 16-28.

15. Alsiede MM, Abddrahman MA, Saeed AE. Phytochemical screening, tota phenolics content and antioxidants activity of Cassia Singueana. J. Med. Plants. 2015; 3(5):160-5.

16. Adzu B, Abbah J, Vongtau H, Gamaniel K. Studies on the use of Cassia singueana in malaria ethnopharmacy. J. Ethnopharmacol. 2003; 88(2-3): 261-267.

17. Kareru PG, Gachanja AN, Keriko J M. Antimicrobial International activity of some medicinal plants used by herbalists. Afri. J. Tradt. Complement. Altern. Med. 2008; 5(1): 51-55

18. Sultana S, Asif HM, Akhtar N, Waqas M, Rrhman SU. Comprrehensive review on ethanobotanical uses, phytochemistry and pharmacological properties of Melia zedarach Inn. Asian J. Pharm. Res. Health Care. 2014; 6(1): 26-32

19. Ervina M, Sukardiman. A review: Melia azedarach L. as a potent anticancer drug. Pharmacogn. Rev. 2018; 12: 94-102.

20. Jain R, Jain SK. Traditional medicinal plants as anticancer agents from Chhattishgarh, India: An overview. Int. J.Phytomed. 2010; 2(3): 186-196.

21. Ahmed MF, Rao AS, Ahemad SR and Ibrahim M. Phytochemical Studies and Hepatoprotective activity of Melia azedarach Linn, against $\mathrm{CCl} 4$ induced Hepatotoxicity in rats. J. Pharm. Res. 2012; 5: 2664-2667

22. Al-Asmari AK, Albalawi SM, Athar MT, Khan AQ, Al-Shahrani H, Islam M Moringa oleifera as an anti-cancer agent against breast and colorectal cancer cell lines. PloS one 2015; 10 (8):e0135814

23. Anwar F, Latif S, Ashraf M, Gilani AH. Moringa oleifera: a food plant with multiple medicinal uses. Phytother. Res. 2007; 21(1):17-25

24. Maroyi A. Lanne adiscolor: Its botany, ethnomedicinal uses, phytochemistry and pharmacological properties. Asian J. Pharm.Clin. Res. 2018; 11(10):49-54.

25. Uma S, Seema B. Vinod KG. Effect of seasonal variation on secondary metabolites of medicinal plants. Int. J. Pharm. Sci. Res. 2015; 6(9): 3654-3662.

26. Yao L, Caffin N, D’Arcy N, Jiang B, ShiY, Singanuusong J, Liu R, Datta X, Kakuda N $\mathrm{Xu}$ Y.. Seasonal variations of phenolic compounds in Australia-grown tea (Camellia sinensis). J. Agri. Food Chem. 2005; 3(16) 6477-6483.

27. Sahoo KP, Pawan K, Kasera and Mohammed S. Secondary metabolites produced during different seasons in some arid medicinal plants. Jai Narain Vyas University, India. Asian J. Plant Sci. Res. 2012; 2 (6): 650-652.

28. Ramakrishna A, Ravishankar GA. Influences of abiotic stress signals on secondary metabolites in plants. Plant Signal. Behav. 2011; 6 (11):1720 - 1731.

29. Asma A, Summiya F, Wajid M. Impact of Different Environmental Temperature on Chemical Composition of Asparagus densiflorussprengeri L. Collected from Different Areas of Punjab, Pakistan. J. Biochem. Micro.Toxico. 2018; 1(103):2.

30. Mpofu A, Sapirstein H, Beta T. Genotype and environmental variation in phenolic content, phenolic acid composition and antioxidant activity of hard spring wheat. J. Agri. Food Chem. 2006; (54):1265-1270.

31. Gololo SS, Shai LJ, Agyei NM, Mogale MA. Effect of seasonal changes on the quantity of phytochemicals in the leaves of three medicinal plants from Limpopo province, South Africa. J. Pharmaco. Phytother. 2016; 8(9): 168-172.

32. World Health Organization. African Health Monitor: Traditional Medicine, our culture our future. A magazine of the World Health Organization Regional Office for Africa: Brazzaville, Congo. 2003; 4(1): 1-43.

33. Araruna MKA, Santos KKA, Costa JGM, Coutinho HDM, Boligon AA, Stefanello $\mathrm{ST}$, et al. Phenolic composition and in vitro activity of the Brazilian fruit tree Caryocarcoriaceum Wittm. European J. Int. Med.2013; 5: 178-183.

34. Tembo DT, Holmes MJ, Marshall LJ. Effect of thermal treatment and storage on bioactive compounds, organic acids and antioxidant activity of baobab fruit (Adansonia digitata) pulp from Malawi. J. Food Compos. Anal. 2017; 58:40-51.

35. Nostro N, Germano M, Angelo VD, Cannatelli M. Extraction methods and bioautography for evaluation of medicinal plant antimicrobial activity. Letters in App. Microbio. 2000; (30):379-384

36. Mwamatope B, Tembo D, Chikowe I, Kampira E, Nyirenda C. Total phenolic contents and antioxidant activity of Senna singueana, Melia azedarach, Moringa oleifera and Lannea discolor herbal plants, Scientific African. 2020: e00481.

37. Fazel S, Hamidreza M, Rouhollah G, Mohammadreza V. Spectrophotometric determination of total alkaloids in some Iranian medicinal plants. Thai J. Pharmaceut. Sci. 2008; 32:17-20

38. Singleton VL, Orthofer R, Lamuela RRM. Analysis of total phenols and other oxidation substrates and antioxidants by means of Folin-Ciocalteu reagent. Methods Enzymol. 1999; 299:152-178.

39. Marinova D, Ribarova F, Atanassova M. Total phenolic and total flavonoids in Bulgarian fruits and vegetables. J. Univ. Chem. Technol. Metallurgy. 2005; 40(3):255-260.

40. Sun Y, Qiao L, Shen Y, Jiang P, Chen J, Ye X. Phytochemical Profile and Antioxidant Activity of Physiological Drop of Citrus Fruits. J. Food Sci. 2013; 78(1):37-42.

41. Benzie IFF, Strain JJ. The ferric reducing ability of plasma (FRAP) as a measure of 'antioxidant power': the FRAP assay. Anal. Biochem. 1996; 239:70 -76.

42. Pimpão RC, Dew T, Oliveira PB, Williamson G, Ferreira RB, Santos CN. Analysis of Phenolic Compounds in Portuguese Wild and Commercial Berries after Multienzyme Hydrolysis. J. Agri. Food chem. 2013; 61(17):4053-6.
43. Quideau S, Deffieux D, Douat-Casassus C, Pouyse'gu L. Plant polyphenols: chemical properties, biological activities and synthesis. Angew. Chem. Int Ed. 2011; (50):586 -621.

44. Marcio C, Isabel CFR. The role of the phenolic compounds in the fight against cancer - a review. Ant-cancer agents in med. Chem. 2013; 13(8): 1236-1258.

45. Watoo P, Kanchalee J, Sakchai WS. Influence of seasons, different plant parts and plant growth stages on saponin quantity and distribution in Bacopamonnieri. Songklanakarin. J. Sci. Tech. 2011; 3(2):193-199.

46. Kale VS: Variable Rates of Primary and Secondary Metabolites during Different Seasons and Physiological Stages in Convolvulus, Withania and Datura. Asian J. Exp. Biol. Sci. 2010; 10(1):50-53

47. Wurtzel ET, Kutchan TM. Plant metabolism, the diverse chemistry set of the future. Sci. 2016; 353:1232-6.

48. Chinnusamy V, Schumaker K, Zhu JK. Molecular genetics perspectives on cross-talk and specificity in abiotic stress signaling in plants. J. Exp. Bot. 2004; 55(395): 225-236.

49. Isah T. Stress and defense responses in plant secondary metabolites production. Biol. Res. 2019; 52(1):39

50. Narayani M, Srivastava S. Elicitation: a stimulation of stress in in vitro plant cell/ tissue cultures for enhancement of secondary metabolite production. Phytochem. Rev. 2018; 16(6):1227-1252

51. De Luca V, Salim V, Atsumi SM, Yu F. Mining the biodiversity of plants: a revolution in the making. Sci. 2012; 336(6068):1658-1661.

52. Hanover JW. Genetics of terpenes. I. Gene control of monoterpene levels in Pinusmonticola Dougl. Heredity. 1966; 21:73-84.

53. Mithen R, Raybould AF, Giamoustaris A. Divergent selection for secondary matabolites between wild populations of Brassica oleracea and its implications for plant-herbivore interactions. Heredity. 1995; 75(5):472-484.

54. Spencer JPE. Flavonoids and related compounds: Bioavailability and function. Florida: CRC Press. 2012; 1-186.

55. Mir AQ, Yazdani T, Ahmad S, Yunus M: Total Flavonoids and Phenolics in Catharanthusroseus L. and Ocimum sanctum L. as Biomarkers of Urban Auto Pollution. Caspian J. Env. Sci. 2009; 7(1): 9-16

56. Courdavault V, Papon N, Clastre M, Giglioli-Guivarc N, St-Pierre B, Burlat V. A look inside an alkaloid multisite plant: the Catharanthus logistics. CurrOpin Plant Biol. 2014; 19:43-50.

57. Lu JJ, Bao JL, Chen, XP, Huang M, Wang YT. Alkaloids isolated from natura herbs as the anticancer agents. Evid. Based Complement. Altern. Med. 2012; 2012: 12.

58. Yang L, Stöckigt J. Trends for diverse production strategies of plant medicinal alkaloids. Nat Prod Rep. 2010; 27(10):1469-1479.

59. Balasundram, N., Sundram, K. and Samman, S. Phenolic compounds in plants and agri-industrial by-products: antioxidant activity, occurrence and potential uses. Food Chem. 2006; 99: 191-203.

60. Sati P, Pandey A, Rawat S, Rani A. Phytochemicals and antioxidants in leaf extracts of Ginkgo biloba with reference to location, seasonal variation and solvent system. J. Pharma. Res. 2013; 7(9):804-809.

61. Sandeep RP, Mansingraj SN, Nilesh VP, Rajaram PP, Ghansham BD. Seasonal Discrepancy in phenolic content and Antioxidant Properties From Bark of Nothapodytes nimmoniana. Int. J. Pharma. Bio Sci. 2010;1(3):1- 17.

62. Rice-Evans CA, Miller NJ, Paganga G. Structure antioxidant activity relationships of flavonoids and phenolic acids. Free Radical Biology and Medicine 1996; 20: 933-956.

63. Burda S, Oleszek W. Antioxidant and antiradical activities of flavonoids. J. Agri Food Chem. 2001; 49: 2774-2779.

64. Tavarini S, Degl'Innocenti E, Remorini D, Massai R, Guidi L. Antioxidant capacity, ascorbic acid, total phenols and carotenoids changes during harvest and after storage of Hayward kiwifruit. Food Chem. 2008; 107: 282-288.

65. Olajire AA, Azeez L. Total antioxidant activity, phenolic, flavonoid and ascorbic acid contents of Nigerian vegetables. African J. Food Sci. Tech. 2011; 2: 22-29.

66. Tabart J, Kevers C, Pincemail J, Defraigne JO, Dommes J. Comparative antioxidant capacities of phenolic compounds measured by various tests. Food Chem 2009; 113(4): 1226-1233.

67. Paixao, N., R. Perestrelo, J. C. Marques and J. S. Camara Relationship between antioxidant capacity and total phenolic content of red, rose and white wines. Food Chem.2007; (105): 204-214.

68. Munir A, Sultana B, BabarT, Bashir A, Amjad M and Hassan Q. Investigation on the Antioxidant Activity of Leaves, Fruit and Stem Bark of Dhraik (Melia azedarach). European J. App. Sci. 2012; 4: 47-51

69. Soobrattee, M.A.; Neergheen, V.S.; Luximon-Ramma, A.; Aruoma, O.I.; Bahorun, T. Phenolics as potential antioxidant therapeutic agents: Mechanism and actions Mutat. Res. 2005; 579: 200-213.

70. Sobeh M, Mahmoud MF, Hasan RA, Cheng H, El-Shazly AM, Wink M. Senna singueana: Antioxidant, Hepatoprotective, Antiapoptotic Properties and Phytochemical Profiling of a Methanol Bark Extract. Molecules. 2017; 22(9):1502.

71. Mondal, A. Phenolic constituents and traditional uses of Cassia (Fabaceae) plants: An update. Org. Biomol. Chem. 2014; 3: 93-141 
72. Abreu IN, Mazzafera P. Effect of water and temperature stress on the content of active constituents of Hypericumbrasiliense Choisy. Plant Physiol. Biochem. 2005; 43(3):241-248

73. Gray DE, Pallardy SG, Garrett HE. Effect of acute drought stress and time of harvest on phytochemistry and dry weight of St. John's wort leaves and flowers. Planta Med. 2003; 69(11):1024-1030.

74. Selmar D, Kleinwachter M. Stress enhances the synthesis of secondary plant products: the impact of stress-related over-reduction on the accumulation of natural products. Plant Cell Physiol. 2013; 54(6):817-826.

75. Zobayed SMA, Afreen F, Kozai T. Phytochemical and physiological changes in the leaves of St. John's wort plants under a drought stress condition. Environ. Exp. Bot. 2007; 59:109-116.

76. Chen S, Andreasson E. Update on glucosinolate metabolism and transport Plant Physiol. Biochem. 2001; 39: 743-758.

77. Nicholas CC. Structure and biogenesis of the cell walls of grasses, Annu. Rev. Plant Physiol. Plant Mol. Biol. 1996; 47:445-476.

78. Qualley A, Dudareva N. Aromatic volatiles and their involvement in plant defense." Induced plant resistance to herbivory. Springer, Dordrecht, 2008. 409-432

79. Fan F, Sang LX, Jiang M. Catechins and Their Therapeutic Benefits to Inflammatory Bowel Disease. Molecules. 2017; 22(3): 484

80. Jeyamani S VP, Senthilnathan B, Balaji P, Masilamani K, Murugan M. Phytochemical Evaluation and HPTLC Fingerprinting Profile of Melia Azedarach Lin and Piper Longum. Indo American J. Pharmaceut. Res. 2017; 7(10).

81. Ervina M, Sukardiman. A review: Melia azedarach L. as a potent anticancer drug. Pharmacogn. Rev. 2018; 12: 94-102.

82. Carpinella MC, Ferrayolic CG, Palacios SM. Antifungal synergistic effect of scopoletin, a hydroxycoumarin isolated from Melia azedarach L. fruits. J. Agri. Food Chem. 2005; 53: 2922-2927.
83. Cezarotto VS, Giacomelli SR, Vendruscolo MH, Vestena AS, Cezarotto CS, da Cruz RC, etal. Influence of Harvest Season and Cultivar on the Variation of Phenolic Compounds Composition and Antioxidant Properties in Vacciniumashei Leaves. Molecules.2017; 22: 1603.

84. Zhang, M.; Hettiarachchy, S.N.; Horax, R.; Kannan, A.; Praisoody, M.D.A. Muhundan, A.; Mallangi, C.R. Phytochemicals, antioxidant and antimicrobial activity of Hibiscus sabdariffa, Centellaasiatica, Moringa oleifera and Murrayakoenigii leaves. J. Med. plants Res.2011;5: 6672-6680.

85. Prakash, D.; Suri, S.; Upadhyay, G.; Singh, B.N. Total phenol, antioxidant and free radical scavenging activities of some medicinal plants. Int. J. Food Sci. Nut. 2007; 58:18-28.

86. Lalas S, Tsaknis J. Extraction and identification of natural antioxidants from the seeds of Moringa oleifera tree variety of Malavi. J. Am. Oil Chem. Soc. 2002; 79: 677-683.

87. Leone A, Spada A, Battezzati A Schiraldi A Aristil J, Bertoli S. Cultivation, Genetic, Ethnopharmacology, Phytochemistry and Pharmacology of Moringa oleifera Leaves: An Overview. Int. J. Mol. Sci. 2015; 16: 12791-12835.

88. Ndhlala AR, Mulaudzi R, Ncube B, Hafiz AA, du Plooy CP Staden JV. Antioxidant, Antimicrobial and Phytochemical Variations in Thirteen Moringa oleifera Lam. Cultivars. Molecules 2014; 19: 10480-10494.

89. Shi B, Zhang W, Li X, Pan X. Seasonal variations of phenolic profiles and antioxidant activity of walnut (Juglans sigillata Dode) green husks. Int. J. Food Prop. 2017 20(3): S2635-S2646.

90. Routray W, Orsat V. Variation of phenolic profile and antioxidant activity of North American highbush blueberry leaves with variation of time of harvest and cultivar. Ind. Crops Prod.2014; 62:147-155.

91. Costa G, Grangeia, Figueirinha A, Figueiredo IV, Batista MT. Influence of harvest date and material quality on polyphenolic content and antioxidant activity of Cymbopogoncitratus infusion. Ind. Crops Prod. 2016; 83:738-745
GRAPHICAL ABSTRACT
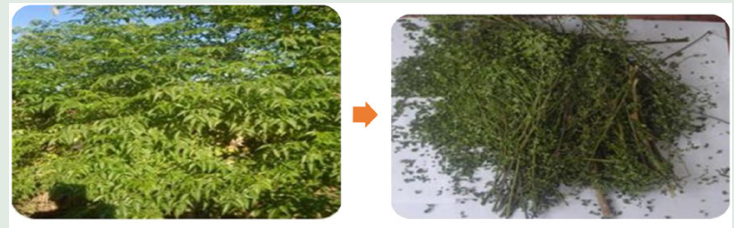

(1.
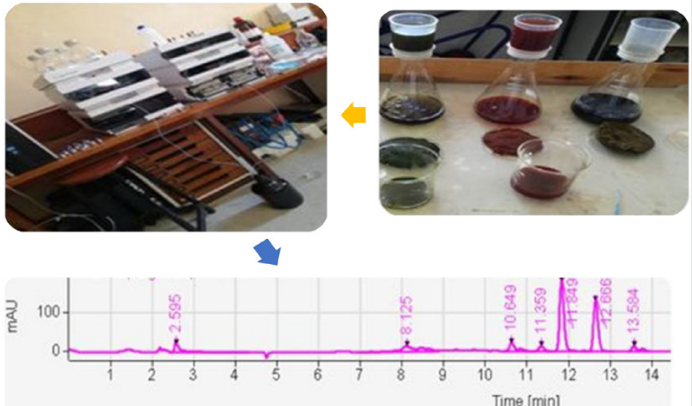

\section{SUMMARY}

- The phytochemical constituents in medicinal plants are subject to seasonal variations which in turn influence the optimum season of harvesting.

- Hot-dry season is the optimum time for harvesting stem barks of L. discolor while hot-wet season represents the optimum harvest time of M. oleifera, S. singueana and M. azedarach leaves.

\section{ABOUT AUTHORS}

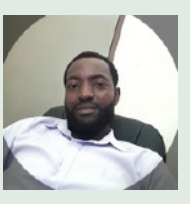

Bonface Mwamatope, Biomedical Sciences, College of Medicine, University of Malawi. P/ Bag 360, Blantyre 3. Malawi.

Cite this article: Mwamatope B, Tembo D, Kampira E, Maliwichi-Nyirenda C, Ndolo V. Seasonal Variation of Phytochemicals in Four Selected Medicinal Plants. Pharmacog Res. 2021;13(4):218-26. 